\title{
BENJAMIN CONSTANT, Journaux intimes
}

\section{Lise Sabourin}

\section{CpenEdition \\ Journals}

\section{Édition électronique}

URL : http://journals.openedition.org/studifrancesi/15514

DOI : 10.4000/studifrancesi. 15514

ISSN : 2421-5856

\section{Éditeur}

Rosenberg \& Sellier

\section{Édition imprimée}

Date de publication : 1 décembre 2018

Pagination : 499-500

ISSN : 0039-2944

\section{Référence électronique}

Lise Sabourin, « BenJamin constant, Journaux intimes », Studi Francesi [En ligne], 186 (LXII | III) | 2018, mis en ligne le 01 janvier 2019, consulté le 05 janvier 2021. URL : http://journals.openedition.org/ studifrancesi/15514; DOI : https://doi.org/10.4000/studifrancesi.15514

Ce document a été généré automatiquement le 5 janvier 2021.

\section{(c) (†)}

Studi Francesi è distribuita con Licenza Creative Commons Attribuzione - Non commerciale - Non opere derivate 4.0 Internazionale. 


\title{
BENJAMIN CONSTANT, Journaux intimes
}

\author{
Lise Sabourin
}

\section{RÉFÉRENCE}

BENJAMIN CONSTANT, Journaux intimes, édition de Jean-Marie Roulin, Paris, Gallimard, 2017, «Folio classique», $1144 \mathrm{pp}$.

1 Inédits du vivant de leur auteur qui les tenait pour soi et non avec intention de les publier, les trois Journaux de Benjamin Constant qu'offre ce volume de la collection de poche «Folio-classique» chez Gallimard permettent de suivre le penseur dans le quotidien de ses actes et de ses pensées de 1804 à 1816 . Cet ensemble, partiellement et inexactement publié par ses héritiers en 1887 , ne connut une véritable parution générale qu'en 1952 après le dépôt des trois manuscrits qui le constituent à la bibliothèque cantonale et universitaire de Lausanne, la ville natale de l'écrivain. JeanMarie Roulin en donne ici une édition soigneusement annotée, avec index biographique des noms propres, bibliographie et en annexe «Amélie et Germaine», ce prolégomène qui pose déjà toutes les oscillations entre l'ennui auprès de l'épouse paisible et la bataille avec la maîtresse intellectuelle qui marquent sans cesse la vie et la pensée du futur auteur d'Adolphe. L'éditeur critique délivre aussi une efficace préface (pp. 7-35) qui précise bien les enjeux et les problématiques de cet écrit par lequel Constant invente, sans doute sans le savoir vraiment, le genre du journal intime moderne.

2 Le premier journal est commencé le 22 janvier 1804 à Weimar, l'effervescente capitale de Thuringe alors animée par les grands noms du Sturm und Drang (Herder mort juste avant, Goethe, Schiller, les frères Schlegel, Schelling et Wieland), que Constant, évincé du Tribunat depuis 1802, découvre en compagnie de Mme de Staël, désireuse de connaître cette Allemagne qui fera son grand œuvre d'exilée napoléonienne. Constant prend notes des rencontres, pose des réflexions liées à son projet d'ouvrage sur la religion, transcrit les tensions de sa vie affective entre Germaine, Charlotte et Julie Talma dont il narre l'agonie juste avant la fin de cet écrit, le 8 mai 1805. 
3 Le deuxième, dit abrégé vu les codes numériques que Constant invente pour désigner ses activités récurrentes sans avoir à les répéter, va du 22 janvier 1804 jusqu'au 27 décembre 1807: il suit ses déplacements de Paris au lac Léman et Coppet, à Lausanne, Rolle et Genève, puis de nouveau à Paris, Rouen, au château d'Acona, loué par Mme de Staël, ou dans sa propre propriété des Herbages qu'une dette de jeu l'oblige à vendre. Repris par sa perpétuelle tentation politique, mais aussi livré à son indécision passionnelle, Constant semble cette fois regretter la vie paisible d'Allemagne.

4 C'est pourquoi il y revient en compagnie de Charlotte, épousée discrètement en 1808 après sa rupture avec Germaine, au début du troisième journal, quatre ans plus tard, le 13 mai 1811, tenu jusqu'aux premiers jours de la seconde Restauration, le 26 septembre 1816. Constant retourne cependant encore à Coppet et se prend maintenant d'une vaine passion pour Juliette Récamier. Mais les événements de la vie publique lui redonnent le désir d'agir: il mise d'abord sur Bernadotte, puis fréquente les royalistes modérés, avant de rédiger le fameux Acte additionnel aux Constitutions de l'Empire durant les Cent jours, qui l'incite à partir prudemment pour Bruxelles puis Londres après Waterloo. Les préoccupations métaphysiques ne l'ont pas quitté comme l'attestent ses liens avec Juliane Krüdener et la continuation toujours réitérée de son ouvrage De la religion considérée dans sa source. Mais c'est désormais la réflexion politique qui prend le dessus dont les publications progressives constitueront finalement le Cours de politique constitutionnelle en 1818. Cette période est aussi celle de la gestation d'Adolphe, paru en 1816, qui transcrit bien le «déchirement horrible» de toute son existence entre désir de l'ange avec qui partager sa vie et poids du lien une fois constitué.

Jean-Marie Roulin étudie bien l'ambivalence de sa personnalité, toujours partagée entre travail dans l'angoisse de gaspiller son temps et son talent, besoin de sociabilité comme enrichissement à sa pensée et ses lectures, crainte de la dispersion et instabilité de ses passions entrelacées. La forme du journal convient à sa dualité, car, écrite avec sincérité, elle lui donne aussi un sentiment d'altérité; elle est pourtant aussi une matrice des œuvres à venir, conférant à son auteur cette liberté à laquelle le futur député libéral fut toujours intrinsèquement attaché sous tous les régimes, politiques comme privés. 